\title{
Osseous metaplasia of the colon in an ulcerative proctosigmoiditis
}

A 77-year-old woman presented with acute abdominal pain and hematochezia. The patient reported a normal routine colonoscopy 2 years ago. Her long-term medication consisted of statins, allopurinol, and triazolam. Additionally she had a short-term analgesic medication

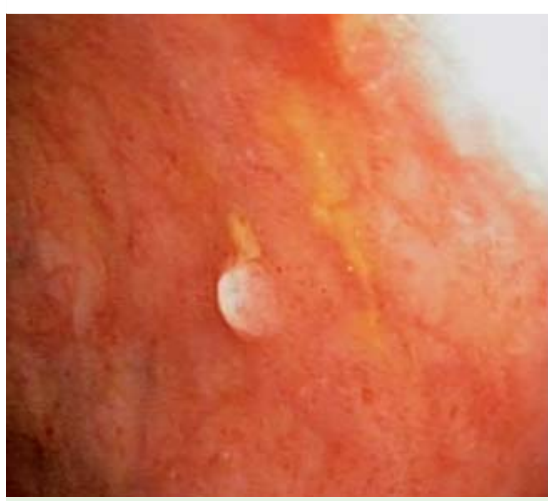

Fig. 1 Endoscopic view of the lesion.

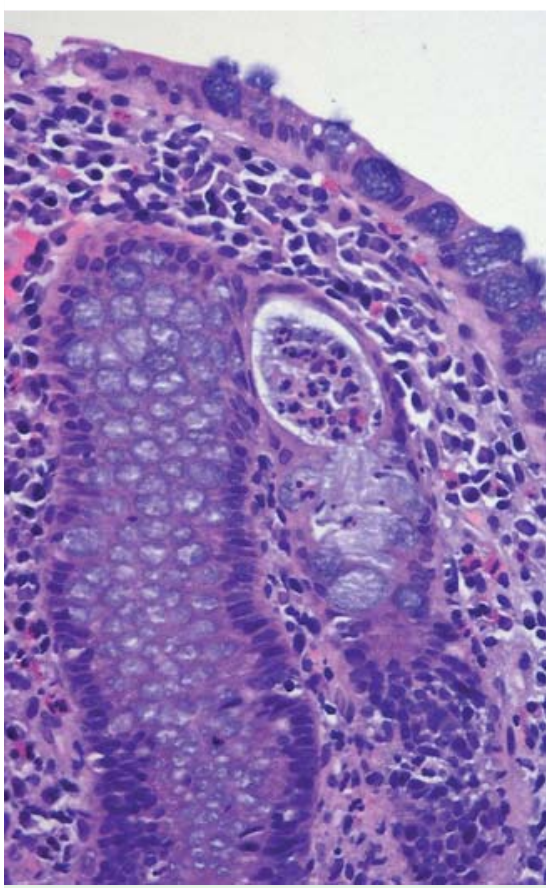

Fig. 2 Microscopic image showing colitis with crypt abscess (hematoxylin and eosin stain, $\times 400)$. (naproxen). At colonoscopy, a marginal macroscopic inflammation of the sigmoid colon and a 4-mm rectal polypoid lesion were visible ( $\bullet$ Fig. 1 ).

During histological examination, a mixed inflammatory infiltrate was visible in the lamina propria, with multiple crypt abscesses ( Fig.2). The polypoid lesion showed hyperplastic crypts and foci of heterotopic bone formation ( Fig.3). Small regions with surface ulceration could be seen. Thus the histopathological diagnosis was ulcerative proctosigmoiditis with metaplastic bone formation. It seems that the bone formation had persisted for a long time and that the finding of ulcerative colitis was overlaid by an infectious component. Due to a normal number of leukocytes in the blood sample, and unremarkable stool samples, a parasitic infection was excluded.

Heterotopic ossification in the gastrointestinal tract is described predominantly in mucin-producing carcinomas of the colon [1]. Descriptions of ossification within inflammatory gastrointestinal lesions are extremely rare, and the pathological mechanisms remain unclear. Sperling et al. assumed that bone-forming osteoblasts differentiate from immature fibroblasts [2]. Rifas et al. demonstrated that T-cell cytokines regulate the differentia- tion process of human mesenchymal stromal cells into osteoblasts by inducing bone morphogenetic protein-2 (BMP-2) [3]. Yu et al. reported that an active actin receptor-like kinase-2 (ALK2), activated by BMP receptor 1 , leads to ectopic bone formation [4]. Finally, Shafritz et al. showed that overexpression of BMP-4 in lymphocytes is associated with ectopic osteogenesis in fibrodysplasia ossificans progressiva [5]. Overall, chronic inflammatory processes seem to play an important role in ectopic bone formation.

Endoscopy_UCTN_Code_CCL_1AD_2AJ

Competing interests: None

\section{Veits ${ }^{1,2}$, A. Perathoner ${ }^{3}$, C. Profanter ${ }^{3}$, C. Falkeis ${ }^{1,2}$, G. Mikuz ${ }^{1}$, C. Ensinger ${ }^{1}$}

${ }^{1}$ Institute of Pathology, Medical University of Innsbruck, Innsbruck, Austria

${ }^{2}$ Institute of Pathology, Klinikum Bayreuth, Bayreuth, Germany

${ }^{3}$ Department of Visceral, Transplant and Thoracic Surgery, Medical University of Innsbruck, Innsbruck, Austria

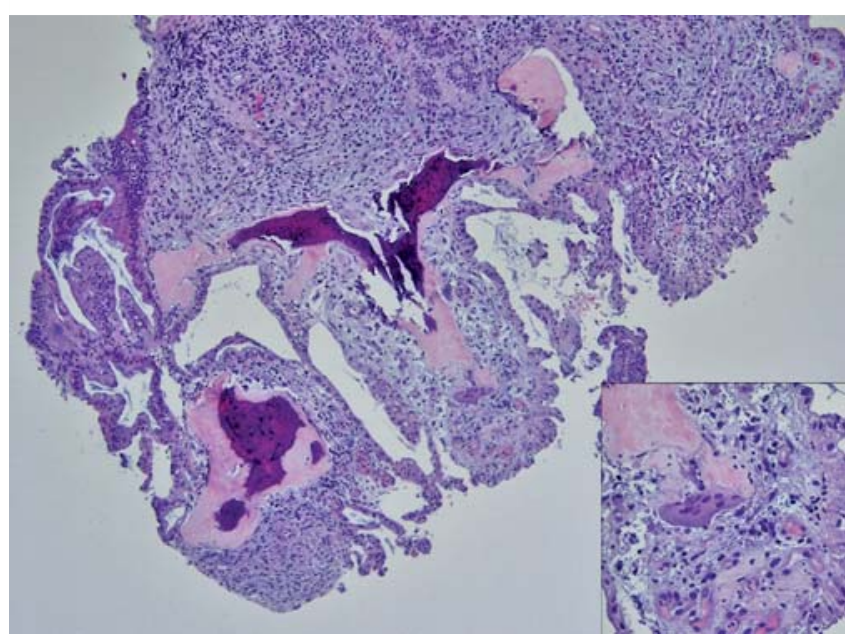

Fig. 3 Microscopic image showing colitis with heterotopic ossification, ulceration, and an osteoclastic giant cell (shown also in enlarged inset) (hematoxylin and eosin stain, $\times 40$ ). 


\section{References}

1 Haque S, Eisen RN, West $A B$. Heterotopic bone formation in the gastrointestinal tract. Arch Pathol Lab Med 1996; 120: 666-670

2 Sperling MH, Friedman CJ. Osseuous metaplasia in a benign colon polyp. Gastrointest Endosc 1981; 27: 198-199

3 Rifas L. T-Cell Cytokine Induction of BMP-2 Regulates Human Mesenchymal Stromal Cell Differentiation and Mineralization. J Cell Biochem 2006; 98: 704-714
4 Yu PB, Deng DY, Lai CS et al. BMP type I receptor inhibition reduces heterotopic ossification. Nat Med 2008; 14: 1363 -1369

5 Shafritz AB, Shore EM, Gannon FH et al. Overexpression of an osteogenic morphogen in fibrodysplasia ossificans progressiva. N Engl J Med 1996; 335: 555-561

\section{Bibliography}

Dol http://dx.doi.org/ 10.1055/s-0031-1291602 Endoscopy 2012; 44: E76-E77 (c) Georg Thieme Verlag KG Stuttgart · New York ISSN 0013-726X

\section{Corresponding author}

\section{Veits, MD}

Institute of Pathology

Klinikum Bayreuth

Preuschwitzerstraße 101

95445 Bayreuth

Germany

Fax: +49-921-4005609

lothar.veits@klinikum-bayreuth.de 